\title{
Loss of nonclassical MHC molecules MIC-A/B expression during progression of uveal melanoma
}

\author{
CS Vetter', W Lieb², E-B Bröcker' and JC Becker*,I \\ 'Department of Dermatology, University of Wuerzburg, Josef-Schneider-Str. 2, 97080 Wuerzburg, Germany; ${ }^{2}$ Department of Ophthalmology, \\ St Vincentius-Hospital gAG, Steinhaeußerstr. 18, 76135 Karlsruhe, Germany
}

\begin{abstract}
Uveal melanoma differs from cutaneous melanoma with respect to aetiology, metastatic behaviour and immune biology. The notion that loss of classical MHC class I molecules in uveal melanoma lesions is associated with an improved prognosis suggests that NK cells act as the predominant cells responsible for immune surveillance of this tumour. Consequently, immune escape mechanisms of uveal melanoma should impair the innate immunity. To this end, expression of the ligand for the NK receptor NKG2D, that is, MIC-A/B was expressed by $50 \%$ of primary tumours, but none of the metastatic lesions. $\mathrm{MIC}^{+}$tumours were characterised by a NKG2D ${ }^{+}$ infiltrate, which was absent in $\mathrm{MIC}^{-}$lesions subsequent to chemoimmune therapy. Strikingly, MIC-A/B expression in metastatic lesions was observed subsequent to chemotherapy with fotemustine in one case. In summary, MIC/NKG2D interactions seem to be involved in the immune surveillance of primary uveal melanomas, whereas for metastatic tumours this ligand/receptor system seems not to be relevant, thus, suggesting an immune selection of MIC negative tumour cells.

British Journal of Cancer (2004) 91, |495- |499. doi:I0.1038/sj.bjc.6602I 23 www.bjcancer.com

Published online 21 September 2004

(c) 2004 Cancer Research UK
\end{abstract}

Keywords: uvea; MIC-A/B; melanoma; NKG2D; NK

Most malignant melanomas in the ocular region arise in the uveal tract. Little is known about its underlying molecular pathogenesis since no genes and tumour-suppressor pathways have so far been convincingly linked to it (Edmunds et al, 2002). The annual incidence of uveal melanoma is in the range of $0.47-0.79$ new cases per 100000 individuals (Woll et al, 1999). Despite its lower incidence compared to cutaneous melanoma, uveal melanoma accounts for about $13 \%$ of all deaths from melanoma (Albert et al, 1992). Uveal melanoma preferentially disseminates haematogenously to the liver and occurrence of metastases is associated with a median survival time of less than 5 months (Eskelin et al, 1999). For cutaneous melanoma substantial advances in the understanding of its pathogenesis have been achieved (Chin et al, 1998). Among these is the recent detection of mutations in the BRAF gene (Davies et al, 2002). Notably, BRAF is not mutated in uveal melanoma (Edmunds and Kelsell, 2002; Cohen et al, 2003), which highlights the molecular differences between uveal and cutaneous melanoma and may explain both the different metastatic behaviour as well as immune biology of these tumours (Naus et al, 2000; Soufir et al, 2000). This could, for example, be the consequence of reduced HLA class I antigen expression; a decrease thereof in cutaneous melanoma is characteristic for tumour progression and represents an important tumour escape mechanism (Garrido et al, 1993; Hicklin et al, 1999). Although almost all

*Correspondence: Professor Dr JC Becker; E-mail: becker_jc @klinik.uni-wuerzburg.de

Received I 4 November 2003; revised 6 July 2004; accepted 6 July 2004; published online 21 September 2004 possible HLA class I antigen loss described for cutaneous melanoma (Algarra et al, 2000) may occur in uveal melanomas (Jager et al, 2002), it is important to note that metastases of uveal melanoma have a similar or even an increased expression of MHC molecules as compared to the primary tumour (Blom et al, 1997b). Moreover, loss of HLA class-I expression in primary tumours is associated with an improved survival and a lower occurrence of metastases (Blom et al, 1997a; Ksander and Chen, 1999; Ericsson et al, 2001). Since loss of HLA class I antigens renders cells more sensitive to NK cell mediated lysis, it has been speculated that the immune surveillance of uveal melanomas is based on NK cells (Rothenfusser et al, 2002).

Over the past years it has been established that activating and inhibiting MHC-specific receptors regulate the activity of NK cells. In this respect, NKG2D differs from most other receptors as it exists only in an activating form. The activating killer receptor NKG2D is expressed on both $\alpha / \beta$ and $\gamma / \delta$ T-cells as well as NK cells (Groh et al, 2001). The MHC class I related chain (MIC)-A/B molecules were recently identified as ligands for this receptor. The MIC molecules possess a low degree of homology to other MHC class-I encoded genes (Bahram, 2000). Unlike classical class I molecules MIC-A/B are not associated with $\beta_{2}$-microglobulin and do not bind peptide. MIC-A/B is highly polymorphic in its transmembrane and extracellular region (Stephens, 2001; Collins et al, 2002), and only some MIC-A/B variants are indeed expressed on the cell surface. Our recent observation that primary cutaneous melanoma expresses MIC-A/B and that this expression is downregulated in metastatic lesions (Vetter et al, 2002) prompted us to scrutinise MIC-A/B expression on uveal melanoma. To this end, we demonstrate stage-dependent expression of MIC-A/B in uveal melanoma. 
Table I Clinical course of patients with metastatic lesions

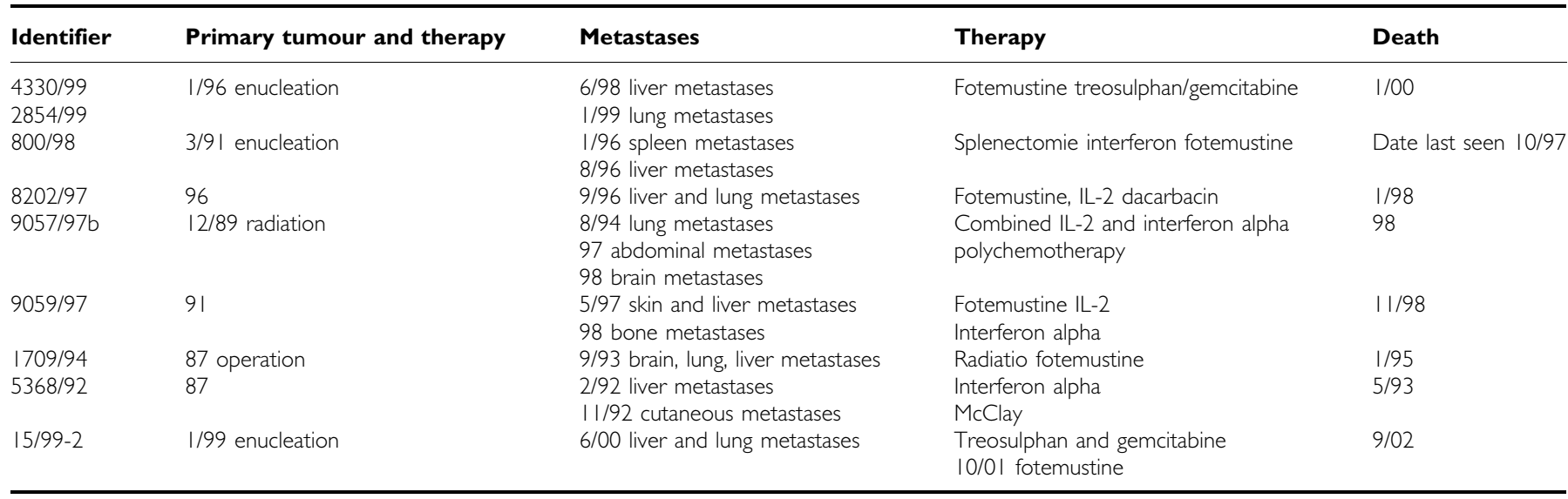

\section{EXPERIMENTAL PROCEDURES}

\section{Tissue samples}

Tumour specimens of primary and metastatic uveal melanoma were obtained by surgical excision. The representative parts of the lesions were used for histological diagnosis and the immediate, next slides were used for scientific workup. Informed consent was obtained from all patients prior to any of these measures. The clinical course of the patients is summarised in Table 1.

\section{Immunohistochemistry}

In total, $5 \mu \mathrm{m}$ sections of paraffin embedded tumours were treated two times with xylol for $10 \mathrm{~min}$ at room temperature. Subsequently, sections were washed three times with ethanol followed by one rinse with distilled water. For antigen retrieval, sections were incubated with citrate buffer, pH 6.0 (DAKO, Hamburg, Germany) for $30 \mathrm{~min}$ at $90^{\circ} \mathrm{C}$ and then air dried for $20 \mathrm{~min}$ at room temperature. Next, slides were rinsed twice with phosphatebuffered saline (PBS, DAKO, S3024) and thereafter incubated with Blocking Solution (DAKO, S2023) for $10 \mathrm{~min}$ at room temperature. After two additional washing steps with PBS for $10 \mathrm{~min}$ at room temperature each, the respective primary monoclonal antibodies $(\mathrm{mAb})$ in $\mathrm{PBS} / 1 \%$ bovine serum albumin (BSA) were added to the sections, which were then incubated for $30 \mathrm{~min}$ at room temperature. The following $\mathrm{mAb}$ were used: MIC-A/B (6D4, murine IgG1), NKG2D (5C6), CD57 (Klon NK-1, Zytomed, Berlin, Germany), CD8 (DAKO, Hamburg, Germany), CD3 (DAKO, Hamburg, Germany); the respective predetermined dilutions ranged from 1:50 to 1:800. After two washes with PBS for $10 \mathrm{~min}$ each, biotinylated species-specific secondary Ab (Dako) were added to the sections. After $25 \mathrm{~min}$ the slides were washed twice with PBS/BSA, and finally the bound antibodies were visualised using streptavidin-HRP or -AEC (DAKO) according to the manufacturer's guidelines.

Histological evaluation and scores were assessed by independent observers (CSV and JCB) to ensure accuracy of quantification of immunohistochemical slides. During a simultaneous session, two observers using the same scale subsequently counted the positive cells per perspective in high-power magnification. A total of 500 cells were examined in at least five areas and the percentage of positive cells was determined to one of the following categories: - : none, $(+)$ : single, $+:>40 \%,++:>80 \%$ positive cells (Lo et al, 2003).

The mAb used for MIC-A/B (6D4) and NKG2D (5C6) were kindly provided by Veronica Groh and Thomas Spies, Fred Hutchinson Cancer Research Center, Seattle, USA and its
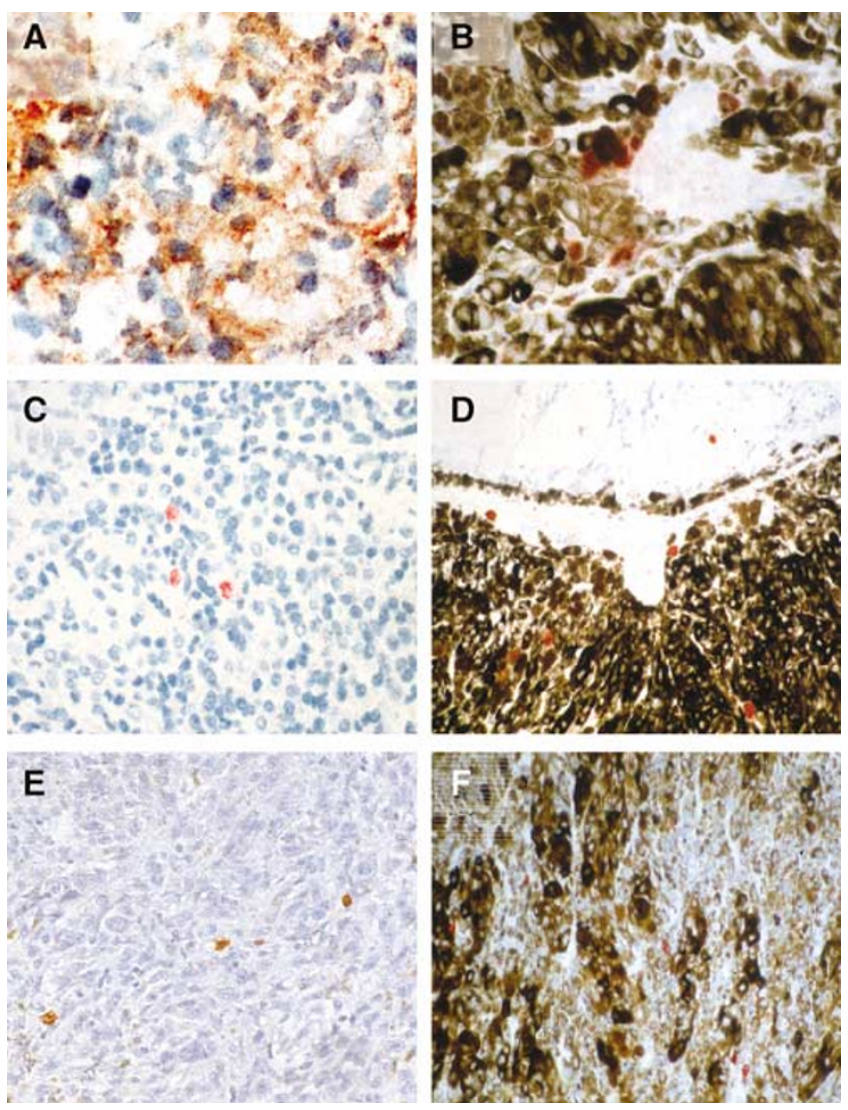

Figure I Expression of MIC (A and B), on two primary uveal melanomas in relation to the presence of infiltrating lymphocytes CD57 $(\mathbf{E}$ and $\mathbf{F})$ and the expression of the activating killer receptor NKG2D ( C and $\mathbf{D})$

characteristics have been described (Bauer et al, 1999; Groh et al, 1999, 2003; Steinle et al, 2001).

\section{RESULTS AND DISCUSSION}

Nine primary uveal melanomas and 11 metastases were analysed by immunohistochemistry for MIC-A/B and NKG2D expression (Figure 1). It should be noted that we did not perform a 
longitudinal study analyzing primary tumours and consecutive metastatic lesions.

We detected MIC-A/B expression on $50 \%$ of the primary tumours (Table 2). The corresponding receptor NKG2D was expressed on a subset of tumour infiltrating lymphocytes present in all $\mathrm{MIC}^{+}$tumours (Table 2). The NK cell marker CD57 was present on majority of infiltrating cells in the MIC/NKG2D positive primary tumours (Figure 1). Interestingly, the magnitude of the inflammatory infiltrate directly correlated with the expression of MIC-A/B on the tumour cells.

In contrast, none of the 10 cutaneous metastases from untreated patients expressed MIC-A/B (Table 3). However, the magnitude of the inflammatory infiltrate in metastases was not correlated with the presence of MIC. This infiltrate largely consisted of $\mathrm{CD}^{+}$cells, but in $50 \%$ of the metastases a considerable number of CD57+ cells were present (Figure 2). Notably, none of these infiltrating cells expressed NKG2D. Due to the small number of cases we did not perform statistical analysis to correlate MIC-A/B and the magnitude of infiltrate, in order not to overestimate the power of our observation.

The quest to establish an effective therapy for metastatic melanoma still remains ajar. This notion holds true particularly for disseminated uveal melanoma, since improvements of the treatment of primary uveal melanoma, enabling the preservation of the eye and its visual function, has not reduced the rate of subsequent tumour dissemination. The range of therapeutic options for stage IV disease encompasses chemotherapeutic, immune, antiangiogenic, and hormonal strategies or a combination thereof. Although the rationale for such combinations, for example chemo-immune therapy, is mostly empiric chemoimmune therapy still is the most promising approach. Notably, the sequence in which chemo- and immune therapies are given, that is, first chemotherapy followed by immunotherapy or vice versa, strongly correlates with the therapeutic activity. The synergistic effect of this combination may be explained by the chemotherapy-induced expression of stress-induced molecules, for example MIC-A/B, on tumour cells, which serve as targets for immune stimulatory molecules such as NKG2D expressed on NK-, $\mathrm{T}$ - and NK/T-cells.

We were able to analyse two metastases from one patient, which had been obtained prior and subsequent to therapy with fotemustine, interferon $\alpha$ and IL2. Notably, prior to chemotherapy neither MIC-A/B nor its receptor NKG2D was detectable in the tumour lesion. After two courses of therapy, however, another subcutaneous metastasis from the same patient was characterised by an intense expression of MIC-A/B on more than $10 \%$ of the tumour cells. This metastasis was further characterised by a dense inflammatory infiltrate of CD3- and CD57-positive cells. This infiltrate also stained positive for NKG2D. Although it cannot be proved that these differences are merely due to lesion heterogeneity, the constant lack of MIC-A/B in all patients not receiving chemotherapy strongly suggests that

Table 2 Uveal melanoma - primary tumours

\begin{tabular}{|c|c|c|c|c|c|c|c|}
\hline \multirow[b]{2}{*}{ No. } & \multirow[b]{2}{*}{ TIL $^{\mathbf{a}}$} & \multicolumn{2}{|c|}{$M I C-A / B^{b}$} & \multicolumn{2}{|c|}{ NKG 2-D' } & \multicolumn{2}{|c|}{ CD $57^{c}$} \\
\hline & & Frequency & Intensity & Frequency & Intensity & Frequency & Intensity \\
\hline $401 / 99$ & $\varnothing$ & - & & - & & - & \\
\hline $331 / 99$ & $(+)$ & $+^{d}$ & + & + & $(+)$ & $(+)$ & + \\
\hline $133 / 99$ & $(+)$ & $(+)$ & $(+)$ & $(+)$ & + & $(+)$ & + \\
\hline 15/99 & + & - & & - & & - & \\
\hline $346 / 98$ & $\varnothing$ & - & & - & & - & \\
\hline $401 / 97$ & $(+)$ & - & & - & & - & \\
\hline $290 / 97$ & $(+)$ & ++ & + & ++ & + & ++ & + \\
\hline $269 / 97$ & $(+)$ & + & + & + & + & + & + \\
\hline $120 / 92$ & + & + & + & + & $(+)$ & + & + \\
\hline
\end{tabular}

${ }^{a}$ The inflammatory infiltrate is classified according to the criteria of Elder and Clark as ++: brisk; +: nonbrisk; (+): dim; $\varnothing$ : absent. ${ }^{b}$ Expression on melanoma cells. ${ }^{\complement}$ Expression on tumour infiltrating lymphocytes. ${ }^{d}-$ : none, $(+)$ : single, $+:<40 \%,++:<80 \%$ positive cells.

Table 3 Uveal melanoma - metastases

\begin{tabular}{|c|c|c|c|c|c|c|c|}
\hline \multirow[b]{2}{*}{ No. } & \multirow[b]{2}{*}{ TIL $^{\mathbf{a}}$} & \multicolumn{2}{|c|}{ MIC-A/B ${ }^{b}$} & \multicolumn{2}{|c|}{ NKG 2-Dc } & \multirow{2}{*}{$\begin{array}{c}\mathrm{CD} 7^{\mathrm{C}} \\
\text { Frequency }\end{array}$} & \multirow{2}{*}{$\begin{array}{c}\text { CD3 }^{c} \\
\text { Frequency }\end{array}$} \\
\hline & & Frequency & Intensity & Frequency & Intensity & & \\
\hline $2616 / 99$ & $(+)$ & - & & - & & - & + \\
\hline $2854 / 99^{d}$ & $(+)$ & - & & - & & - & $(+)$ \\
\hline $4430 / 99$ & + & $+^{e}$ & ++ & ++ & + & + & ++ \\
\hline $800 / 98$ & $(+)$ & - & & - & & + & + \\
\hline $8202 / 97$ & $(+)$ & - & & - & & - & $(+)$ \\
\hline $9057 / 97$ & $(+)$ & - & & - & & + & ++ \\
\hline $9059 / 97$ & $(+)$ & - & & - & & + & + \\
\hline |709/94 & ++ & - & & - & & - & - \\
\hline $3713 / 95$ & $(+)$ & - & & - & & - & + \\
\hline $6830 / 95$ & $(+)$ & - & & - & & $(+)$ & + \\
\hline $7602 / 95$ & $(+)$ & - & & - & & - & $(+)$ \\
\hline $5368 / 92$ & + & - & & - & & $(+)$ & - \\
\hline
\end{tabular}

${ }^{a}$ The inflammatory infiltrate is classified according to the criteria of Elder and Clark as ++: brisk; +: nonbrisk; (+): dim; $\varnothing$ : absent. 'Expression on melanoma cells. 'Expression on tumour infiltrating lymphocytes. ${ }^{d} \# 2854 / 99$ and $4430 / 99$ were obtained from the same patient prior or after therapy with fotemustine. ${ }^{e}-:$ none, $(+)$ : single, + : $<40 \%,++$ : $<80 \%$ positive cells. 

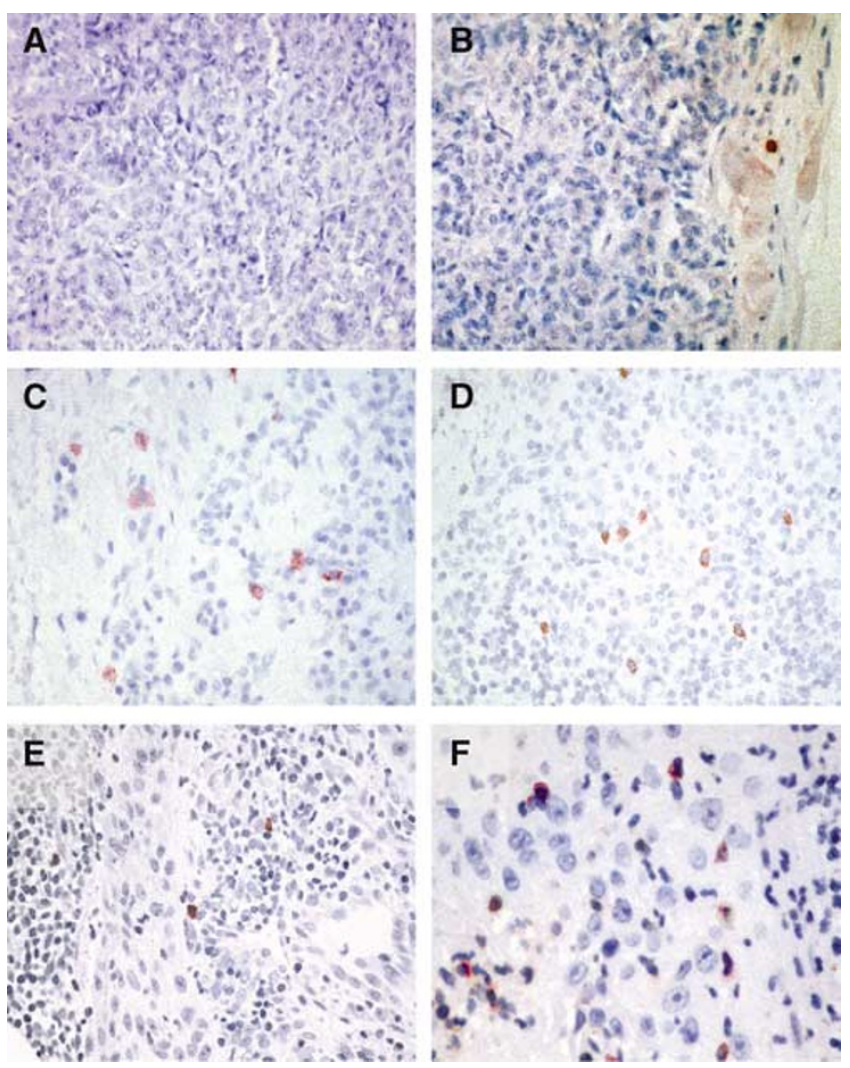

Figure 2 Expression of $\operatorname{MIC}(\mathbf{A}, \mathbf{C}), \operatorname{NKG} 2 \mathrm{D}$ (B, D), CD57 (E), and CD3 $(\mathbf{F})$ on tumour or infiltrating cells of metastatic melanoma in relation to therapy with fotemustine. The sections $\mathbf{A}$ and $\mathbf{B}$ were obtained prior, and the sections $\mathbf{C}-\mathbf{F}$ subsequent to therapy.

MIC expression is indeed induced by the applied therapeutic measures.

The lack of correlation of melanoma-specific immune responses and the clinical course of the disease has provided the impetus to investigate the mechanisms used by malignant cells to escape immune recognition. In this respect, abnormalities in HLA class I expression have been conclusively demonstrated as one of these mechanisms (Campoli et al, 2002). Since NK cell lysis is enhanced by downregulated MHC class I expression, Uveal melanoma may actually represent an exception to this rule (Seliger et al, 2003). Indeed, Ma et al (1995) demonstrated that the sensitivity of human uveal melanoma cells to NK cell lysis was reciprocal to the level of HLA class I expression. Susceptibility to NK lysis also impacts the metastatic behaviour: injection of uveal melanoma cells into eyes of nude mice demonstrated an inverse correlation between development of hepatic metastases and the sensitivity of cell lysis in vitro (Ma and Niederkorn, 1995).

Since NK cells infringe in immune surveillance of uveal melanoma, immunotherapy for these tumours should include strategies influence them and therefore innate immunity. The interaction of NKG2D with MIC-A/B may serve this approach. The MIC gene transcriptional regulatory sequences contain heat-shock elements similar to those in the human Hsp70 promoter. Since genotoxic chemotherapeutic agents such as alkylating, cytotoxic, antimitotic and antimetabolic substances, activate the Hsp70 promoter (Hunt and Morimoto, 1985; Groh et al, 1996) via binding of HSF-1, thereby inducing gene transcription, similar mechanisms, may explain the induction of MIC-A/B expression by fotemustine (Liu et al, 1996). Though induction of MIC-A/B by chemotherapy and subsequent presence of an $\mathrm{NKG}_{2} \mathrm{D}^{+}$inflammatory infiltrate was only investigated in one patient, our previous studies in cutaneous melanoma demonstrated changes in the inflammatory infiltrates at different tumour stages, which were associated with changes in MIC-A/B expression (Vetter et al, 2002), thus strengthening the relevance of these findings in this one patient.

In conclusion, MIC/NKG2D interactions are present in the initial phases of an immune response to uveal melanoma, but this interaction seems to be less involved in responses to metastatic disease suggesting immune selection of MIC negative tumour cells. However, cell stresses such as the presence of different cytotoxic agents seem to restore MIC-A/B expression. Even if this notion is based on a case report, it is of particular interest as it links chemoand immunotherapy and explains the synergistic effects of these different therapeutic approaches empirically established in the clinic (Woll et al, 1999).

\section{REFERENCES}

Albert DM, Niffenegger AS, Willson JK (1992) Treatment of metastatic uveal melanoma: review and recommendations. Surv Ophthalmol 36: $429-438$

Algarra I, Cabrera T, Garrido F (2000) The HLA crossroad in tumor immunology. Hum Immunol 61: $65-73$

Bahram S (2000) MIC genes: from genetics to biology. Adv Immunol 76: $1-60$

Bauer S, Groh V, Wu J, Steinle A, Phillips JH, Lanier LL, Spies T (1999) Activation of NK cells and $\mathrm{T}$ cells by NKG2D, a receptor for stressinducible MICA. Science 285: $727-729$

Blom DJ, Luyten GP, Mooy C, Kerkvliet S, Zwinderman AH, Jager MJ (1997a) Human leukocyte antigen class I expression. Marker of poor prognosis in uveal melanoma. Invest Ophthalmol Vis Sci 38: 1865-1872

Blom DJ, Schurmans LR, Waard-Siebinga I, Wolff-Rouendaal D, Keunen JE, Jager MJ (1997b) HLA expression in a primary uveal melanoma, its cell line, and four of its metastases. Br J Ophthalmol 81: 989-993

Campoli M, Chang CC, Ferrone S (2002) HLA class I antigen loss, tumor immune escape and immune selection. Vaccine 20(Suppl 4): A40-A45

Chin L, Merlino G, DePinho RA (1998) Malignant melanoma: modern black plague and genetic black box. Genes Dev 12: 3467-3481

Cohen Y, Goldenberg-Cohen N, Parrella P, Chowers I, Merbs SL, Pe'er J, Sidransky D (2003) Lack of BRAF mutation in primary uveal melanoma. Invest Ophthalmol Vis Sci 44: 2876-2878

Collins RW, Stephens HA, Clare MA, Vaughan RW (2002) High resolution molecular phototyping of MICA and MICB alleles using sequence specific primers. Hum Immunol 63: $783-794$

Davies H, Bignell GR, Cox C, Stephens P, Edkins S, Clegg S, Teague J, Woffendin H, Garnett MJ, Bottomley W, Davis N, Dicks E, Ewing R, Floyd Y, Gray K, Hall S, Hawes R, Hughes J, Kosmidou V, Menzies A, Mould C, Parker A, Stevens C, Watt S, Hooper S, Wilson R, Jayatilake H, Gusterson BA, Cooper C, Shipley J, Hargrave D, Pritchard-Jones K, Maitland N, Chenevix-Trench G, Riggins GJ, Bigner DD, Palmieri G, Cossu A, Flanagan A, Nicholson A, Ho JW, Leung SY, Yuen ST, Weber BL, Seigler HF, Darrow TL, Paterson H, Marais R, Marshall CJ, Wooster R, Stratton MR, Futreal PA (2002) Mutations of the BRAF gene in human cancer. Nature 417: $949-954$

Edmunds SC, Kelsell DP (2002) Double jeopardy: Ras and CDK4 coexpression in skin cancer. Trends Mol Med 8: 548

Edmunds SC, Kelsell DP, Hungerford JL, Cree IA (2002) Mutational analysis of selected genes in the TGFbeta, Wnt, pRb, and p53 pathways in primary uveal melanoma. Invest Ophthalmol Vis Sci 43: 2845- 2851

Ericsson C, Seregard S, Bartolazzi A, Levitskaya E, Ferrone S, Kiessling R, Larsson O (2001) Association of HLA class I and class II antigen expression and mortality in uveal melanoma. Invest Ophthalmol Vis Sci 42: $2153-2156$ 
Eskelin S, Pyrhonen S, Summanen P, Prause JU, Kivela T (1999) Screening for metastatic malignant melanoma of the uvea revisited. Cancer 85: $1151-1159$

Garrido F, Cabrera T, Concha A, Glew S, Ruiz-Cabello F, Stern PL (1993) Natural history of HLA expression during tumour development. Immunol Today 14: 491 - 499

Groh V, Bahram S, Bauer S, Herman A, Beauchamp M, Spies T (1996) Cell stress-regulated human major histocompatibility complex class I gene expressed in gastrointestinal epithelium. Proc Natl Acad Sci USA 93: $12445-12450$

Groh V, Bruhl A, El Gabalawy H, Nelson JL, Spies T (2003) Stimulation of $\mathrm{T}$ cell autoreactivity by anomalous expression of NKG2D and its MIC ligands in rheumatoid arthritis. Proc Natl Acad Sci USA 100: $9452-9457$

Groh V, Rhinehart R, Randolph-Habecker J, Topp MS, Riddell SR, Spies T (2001) Costimulation of CD8alphabeta T cells by NKG2D via engagement by MIC induced on virus-infected cells. Nat Immunol 2: 255-260

Groh V, Rhinehart R, Secrist H, Bauer S, Grabstein KH, Spies T (1999) Broad tumor-associated expression and recognition by tumor-derived gamma delta T cells of MICA and MICB. Proc Natl Acad Sci USA 96: $6879-6884$

Hicklin DJ, Marincola FM, Ferrone S (1999) HLA class I antigen downregulation in human cancers: $\mathrm{T}$-cell immunotherapy revives an old story. Mol Med Today 5: 178-186

Hunt C, Morimoto RI (1985) Conserved features of eukaryotic hsp70 genes revealed by comparison with the nucleotide sequence of human hsp70. Proc Natl Acad Sci USA 82: 6455-6459

Jager MJ, Hurks HM, Levitskaya J, Kiessling R (2002) HLA expression in uveal melanoma: there is no rule without some exception. Hum Immunol 63: $444-451$

Ksander BR, Chen PW (1999) Immunotherapy of uveal melanoma. Dev Ophthalmol 30: 220-230

Liu H, Lightfoot R, Stevens JL (1996) Activation of heat shock factor by alkylating agents is triggered by glutathione depletion and oxidation of protein thiols. J Biol Chem 271: $4805-4812$
Lo ML, Pannone G, Staibano S, Mignogna MD, Rubini C, Mariggio MA, Procaccini M, Ferrari F, De Rosa G, Altieri DC (2003) Survivin expression in oral squamous cell carcinoma. Br J Cancer 89: 2244-2248

Ma D, Luyten GP, Luider TM, Niederkorn JY (1995) Relationship between natural killer cell susceptibility and metastasis of human uveal melanoma cells in a murine model. Invest Ophthalmol Vis Sci 36: 435-441

Ma D, Niederkorn JY (1995) Transforming growth factor-beta downregulates major histocompatibility complex class I antigen expression and increases the susceptibility of uveal melanoma cells to natural killer cell-mediated cytolysis. Immunology 86: 263-269

Naus NC, Zuidervaart W, Rayman N, Slater R, van Drunen E, Ksander B, Luyten GP, Klein A (2000) Mutation analysis of the PTEN gene in uveal melanoma cell lines. Int J Cancer 87: $151-153$

Rothenfusser S, Buchwald A, Kock S, Ferrone S, Fisch P (2002) Missing HLA class I expression on Daudi cells unveils cytotoxic and proliferative responses of human gammadelta $\mathrm{T}$ lymphocytes. Cell Immunol 215: $32-44$

Seliger B, Abken H, Ferrone S (2003) HLA-G and MIC expression in tumors and their role in anti-tumor immunity. Trends Immunol 24: $82-87$

Soufir N, Bressac-de Paillerets B, Desjardins L, Levy C, Bombled J, Gorin I, Schlienger P, Stoppa-Lyonnet D (2000) Individuals with presumably hereditary uveal melanoma do not harbour germline mutations in the coding regions of either the P16INK4A, P14ARF or cdk4 genes. $\mathrm{Br} J$ Cancer 82: 818-822

Steinle A, Li P, Morris DL, Groh V, Lanier LL, Strong RK, Spies T (2001) Interactions of human NKG2D with its ligands MICA, MICB, and homologs of the mouse RAE-1 protein family. Immunogenetics 53: $279-287$

Stephens HA (2001) MICA and MICB genes: can the enigma of their polymorphism be resolved? Trends Immunol 22: 378-385

Vetter CS, Groh V, Thor SP, Spies T, Brocker EB, Becker JC (2002) Expression of stress-induced MHC class I related chain molecules on human melanoma. I Invest Dermatol 118: 600-605

Woll E, Bedikian A, Legha SS (1999) Uveal melanoma: natural history and treatment options for metastatic disease. Melanoma Res 9: 575-581 